\title{
Editorial
}

\section{Clostridium difficile: Responding to a New Threat From an Old Enemy}

\author{
L. Clifford McDonald, MD, FACP
}

It has been 70 years since the initial description of Clostridium difficile and nearly 30 years since the discovery of its role in antibiotic-associated colitis. ${ }^{1,2}$ During the past three decades, we have learned much about this organism, including the function and regulation of its principal toxins, $A$ and $B$, and their role in disease, ranging from the relatively mild forms of pseudomembranous colitis to severe toxic megacolon, sepsis, and even death., ${ }^{3,4} \mathrm{We}$ also have begun to appreciate the function of the host's immune system in the prevention of and recovery from $C$. difficile-associated disease (CDAD) and in the prevention of recurrent disease. ${ }^{5,6}$ The role of $C$. difficile spores, which can contaminate the patient care environment, fomites, and the hands of healthcare workers, in transmission of disease in healthcare settings is now becoming clear. ${ }^{7.9}$ Finally, it appears likely that the use of particular antimicrobials directed at other pathogens, coupled with intrinsic or acquired resistance in C. difficile, may play an important role in epidemic hospital outbreaks. ${ }^{10}$

Despite these advances, we now face what appears to be a new threat from this old enemy. According to the results of one recent national survey, nearly $40 \%$ of U.S. infectious disease physicians have perceived an increase in the incidence of $\mathrm{CDAD}$ during the past 1 to 2 years alone. ${ }^{11}$ Further, growing evidence suggests that the severity of $\mathrm{CDAD}$ is increasing. ${ }^{11-13}$ There are several possible explanations for the changing epidemiology of CDAD. These include changes in antimicrobial use or other drug prescribing, changes in infection control practices, or the emergence of a new strain with increased virulence, antimicrobial resistance, or both.

The Centers for Disease Control and Prevention
(CDC) recently described a novel strain of $C$. difficile that possesses both unique putative virulence factors and increased resistance to the fluoroquinolones; either may provide this strain with selective advantages over other strains. ${ }^{14,15}$ This strain was associated with CDAD outbreaks in seven hospitals in six states (Georgia, Illinois, Maine, New Jersey, Oregon, and Pennsylvania) with onset dates during 2001 to 2004 . Since this report, we have identified outbreaks of this strain in four additional states (Connecticut, Florida, Massachusetts, and Ohio). My CDC colleagues, Dr. George Killgore and Ms. Angie Thompson, shared in the initial characterization of this U.S. epidemic strain and they have, together with domestic and international collaborators, determined this to be the same strain as that causing outbreaks in Quebec, Canada, ${ }^{16,17}$ and, more recently, England. ${ }^{18}$

The first step in responding to this new threat is to further our knowledge about CDAD; four articles in this issue of Infection Control and Healthcare Epidemiology have been written specifically to this end. ${ }^{1922}$ In the first of these, Sohn et al. ${ }^{19}$ report on varying $\mathrm{CDAD}$ rates and surveillance methods among seven tertiary hospitals (ie, the Prevention Epicenter Hospitals). Next, Palmore et al. ${ }^{20}$ report on the risk factors for CDAD among outpatients at a cancer hospital. In the third article, Modena et al. ${ }^{21}$ describe antimicrobial use and other risk factors for CDAD among hospitalized patients during a recent 1-year period. Finally, Rexach et al. ${ }^{22}$ report on a spatial and temporal analysis of CDAD transmission in a pediatric hospital during the late 1990s.

Our first response to the growing threat of CDAD in North American hospitals is to improve surveillance. Sohn et al. detail the challenges to establishing a highly reliable 
surveillance system. ${ }^{19} \mathrm{~A}$ recent report of CDAD surveillance from the National Nosocomial Infections Surveillance (NNIS) System indicated a significant increase in rates among intensive care unit (ICU) patients in larger hospitals (ie, > 500 beds) and in hospital-wide rates of CDAD in smaller hospitals (ie, $<250$ beds) between 1987 and $2001 .^{23}$ In contrast, Sohn et al. report no significant increase during 2000 to $2003 .{ }^{19}$ However, their mean hospital-wide rate (12.1 cases per 10,000 patient-days or 7.4 per 1,000 admissions) is more than twice the rate reported from ICUs of teaching hospitals in the NNIS System during 1987 to 2001 (ie, 5.1 per 10,000 patient-days) and nearly six times the hospitalwide rate of teaching hospitals during the same period (ie, 1.3 per 1,000 admissions). ${ }^{19,23}$

The CDC also reported a relative increase of more than $50 \%$ in the proportion of discharges with International Classification of Diseases, 9th revision (ICD-9)-coded diagnoses of CDAD during 2000 and 2002 among all non-federal U.S. acute care hospitals. ${ }^{24}$ Similar increases in both ICD-9-coded discharge diagnoses and positive laboratory test results for $\mathrm{CDAD}$ were recently reported from Veterans Affairs hospitals across the United States. ${ }^{25}$ However, what was more important from the report of Sohn et al. was the major variation in surveillance case definitions and reported sensitivity and specificity of laboratory tests used by the Prevention Epicenter Hospitals. ${ }^{19}$

First, regarding surveillance case definitions, there was variation in whether hospitals considered CDAD as healthcare associated when patients recently discharged from a healthcare facility experienced community-onset disease. There was also variation in how recurrent cases were counted. Second, regarding laboratory testing, a common assumption is that use of a less sensitive laboratory test will bias $\mathrm{CDAD}$ rates to appear lower than they really are. However, this could in fact increase rates as insensitive tests may delay diagnosis and implementation of infection control precautions and thus allow continued spread of disease. This suggests that laboratories, while considering turnaround time, should use the most sensitive test available. Unfortunately, even the tissue cytotoxin assay, long held as the gold standard for CDAD diagnosis, may miss almost one-third of patients with $C$. difficile infection. ${ }^{26}$ These patients characteristically have lower numbers of toxinogenic organism recovered on stool culture. It may be that an important step in our battle to control $C$. difficile transmission will be the development of more sensitive and rapid diagnostic tests to detect these cases.

Palmore et al. address the issue of how patients with healthcare-associated CDAD may frequently not develop symptoms until after they are discharged; they found that $19 \%$ of cases acquired in a cancer hospital manifested in this way. ${ }^{20}$ Because these patients spent more time as inpatients during the previous 2 months than did control-patients, it is likely that disease-causing organisms were acquired within the hospital. These investigators also report prolonged median intervals between disease onset and last hospital discharge (20.3 days, with a range up to 60 days-which was the limit of their look-back period) and completion of most recent antibiotic therapy (16.5 days, with a range up to 49 days).$^{21}$ Although the official "incubation period" of $C$. difficile is unknown, diarrhea typically has its onset while the patient is still receiving antimicrobial therapy. However, based on communications with infection control personnel at hospitals experiencing recent outbreaks, it seems that delayed disease manifestation may be either more common than previously thought or at least increasing in frequency. Delays of up to 6 or more weeks following cessation of antimicrobial therapy to onset of diarrhea have been previously reported. ${ }^{27}$

Modena et al. highlight methodologic issues for performing epidemiologic investigations of healthcare-associated CDAD ${ }^{21}$ Investigations of outbreaks often entail a case-control study to determine specific antimicrobial risk factors because restriction of specific antimicrobial agents associated with cases is an effective means of bringing at least some outbreaks under control. ${ }^{9,10,28}$ The approach of Modena et al. in selecting control-patients from only those inpatients who received antimicrobial agents makes sense as virtually all healthcare-associated $\mathrm{CDAD}$ cases are associated with some type of antimicrobial exposure..$^{21}$

These authors take an additional step to design a "purer" study of healthcare-associated disease by excluding all case-patients with less than 5 days of antimicrobial exposure prior to $\mathrm{CDAD}$ onset and all control-patients with less than 5 days of total antimicrobial exposure. On the basis of the report by Palmore et al. ${ }^{20}$ we assume that Modena et al. may have excluded a large proportion of cases in which C. difficile was likely transmitted within the healthcare setting but manifested either outside the hospital or during the first few days of antimicrobial therapy within the hospital. ${ }^{21}$ Modena et al. may have also inadvertently biased their results by excluding from analysis CDAD cases precipitated by antimicrobials that more efficiently select for $C$. difficile and therefore manifest with symptomatic disease in less than 5 days. Comparing antimicrobial exposures in cases with onset of symptoms within 5 days with cases with onset after 5 days could detect such a bias.

In neither the Palmore et al. or the Modena et al. study were cases of CDAD independently associated with fluoroquinolone use. . $^{20,21}$ This is in contrast to recent reports of outbreaks of the epidemic strain, which is fluoroquinolone resistant. ${ }^{28,29}$ The antimicrobial agents associated with CDAD in the study by Palmore et al. (ie, clindamycin and third-generation cephalosporins) have been frequently identified in other studies. ${ }^{9,20,27}$ The apparent protective effect of the macrolides found by Modena et al. is novel, but may reflect confounding with another unmeasured variable. ${ }^{21}$ For example, it does not appear that the ward in which the patient resided was analyzed in their study. If $C D A D$ rates varied markedly by ward, the "colonization" pressure (ie, increased risk posed by having many nearby patients who could serve as a source in transmission) may have skewed the data; macrolide use could also vary by ward, making it appear associated with $\mathrm{CDAD}$ when in fact colonization pressure was the true risk factor.

Rexach et al. measured the use of cluster analy- 
sis, or looking for temporal-spatial associations between cases, against DNA fingerprinting for estimating the likelihood of $C$. difficile transmission. ${ }^{22}$ Although they found that cluster analysis had minimal use in this regard, their study was limited by the absence of cultures performed on patient admission and the reliance on stool samples sent to the microbiology laboratory for other reasons, resulting in only $58 \%$ of the study population being sampled. One presumes that most patients had diarrhea at the time their stool sample was collected. This could explain the relatively high rate of $C$. difficile recovery from samples (67 of $256 ; 26 \%$ ), even though $40 \%$ of $C$. difficile isolates were nontoxigenic.

Some children in this study may have been admitted to the hospital with unrelated strains of $C$. difficile but by chance developed diarrhea around the same time and on the same ward as another colonized or diseased child. ${ }^{22}$ In addition, some of the $42 \%$ of children who were never cultured may have become colonized and served as intermediate hosts in transmission. Children in a pediatric hospital are much more likely to have contact with one another in common play areas, leading to isolates with matching DNA patterns despite the fact that they are housed in separate parts of the hospital. Finally, the authors suggest that transmission may occur weeks or months later via contamination of the patient care environment with spores.

The potential of $C$. difficile to be transmitted by such varied means points to the need for additional research into how this pathogen is transmitted most commonly. For example, just how important are asymptomatic, colonized individuals in nosocomial transmission? Or, how commonly do spores that have persisted in the environment for weeks or months lead to transmission? However, given the recognition of an international epidemic of $C$. difficile, we in the infection control community cannot wait until these and other questions are answered to take action in controlling CDAD.

All hospitals should begin to conduct surveillance and track $\mathrm{CDAD}$ case rates if they have not been doing so already. There is currently no standardized surveillance case definition that accounts for all issues raised by these reports ${ }^{19,20}$; however, the $\mathrm{CDC}$ is working toward the development of such a definition. As part of this process, consideration should be given to community-onset disease or disease onset within 48 hours of readmission, providing that the patient has been recently discharged within some time period-this may need to be extended to as long as 3 months rather than the few days to 2 months used in several of the Prevention Epicenter Hospitals. The minimum asymptomatic period off therapy that is predictive of a new infection (vs recrudescence of prior infection) is unknown and determining whether patients are asymptomatic off therapy may significantly increase the workload of CDAD surveillance at most hospitals. Therefore, the primary focus of a case definition should be on initial CDAD cases. Hospitals inexperienced in $\mathrm{CDAD}$ surveillance may be able to detect changes in healthcare-associated disease simply by tracking the number of first positive $C$. difficile labora- tory test results from samples obtained 48 hours or more following admission.

Especially if an increase in rates is noted, clinical outcomes among patients with CDAD should be monitored. If cases appear more severe, special consideration should be given to early diagnosis and treatment of patients. Strict infection control measures including contact precautions should be instituted for all patients with CDAD. ${ }^{30}$ Because alcohol is ineffective in killing $C$. difficile spores, healthcare workers at a facility experiencing an outbreak should wash their hands using soap and water rather than alcohol-based waterless sanitizers when caring for CDAD patients. ${ }^{31}$ Details concerning this and other recommendations, such as enhanced environmental cleaning using dilute bleach to eliminate spores, can be found at the CDC web site (www. cdc.gov/nciod/hip).

As the infection control community around the world responds to this new threat from $C$. difficile, the four reports in this issue of Infection Control and Hospital Epidemiology serve an important function, if not in answering all of our questions, then at least in helping us to frame our questions.

\section{REFERENCES}

1. Hall IC, O'Toole E. Intestinal flora in newborn infants with a description of a new pathogenic anaerobe, Bacillus difficilis. Am J Dis Child 1935;49:390-402.

2. Bartlett JG, Chang T, Taylor NS, Onderdonk AB. Colitis induced by Clostridium difficile. Rev Infect Dis 1979;1:370-378.

3. Bartlett JG. Clinical practice: antibiotic-associated diarrhea. $N$ Engl J Med 2002;346:334-339.

4. Voth DE, Ballard JD. Clostridium difficile toxins: mechanism of action and role in disease. Clin Microbiol Rev 2005;18:247-263.

5. Kyne L, Warny M, Qamar A, Kelly CP. Asymptomatic carriage of Clostridium difficile and serum levels of IgG antibody against toxin A. $N$ Engl J Med 2000;342:390-397.

6. Kyne L, Warny M, Qamar A, Kelly CP. Association between antibody response to toxin $A$ and protection against recurrent Clostridium difficile diarrhoea. Lancet 2001;357:189-193.

7. McFarland LV. What's lurking under the bed? Persistence and predominance of particular Clostridium difficile strains in a hospital and the potential role of environmental contamination. Infect Control Hosp Epidemiol 2002;23:639-640.

8. Samore MH, Venkataraman L, DeGirolami PC, Arbeit RD, Karchmer AW. Clinical and molecular epidemiology of sporadic and clustered cases of nosocomial Clostridium difficile diarrhea. Am I Med 1996;100:32-40.

9. Gerding DN, Johnson S, Peterson LR, Mulligan ME, Silva J Jr. Clostridium difficile-associated diarrhea and colitis. Infect Control Hosp Epidemiol 1995;16:459-477.

10. Johnson S, Samore MH, Farrow KA, et al. Epidemics of diarrhea caused by a clindamycin-resistant strain of Clostridium difficile in four hospitals. N Engl J Med 1999;341:1645-1651.

11. Layton BA, McDonald LC, Gerding DN, Liedtke LA, Strausbaugh LJ. Perceived increases in the incidence and severity of Clostridium difficile disease: an emerging threat that continues to unfold. Presented at the 15 th Annual Scientific Meeting of the Society for Healthcare Epidemiology of America; April 9-12, 2005; Los Angeles, CA. Abstract 66.

12. Dallal RM, Harbrecht BG, Boujoukas AJ, et al. Fulminant Clostridium difficile: an underappreciated and increasing cause of death and complications. Ann Surg 2002;235:363-372.

13. Pepin J, Valiquette L, Alary ME, et al. Clostridium difficile-associated diarrhea in a region of Quebec from 1991 to 2003: a changing pattern of disease severity $C M A J 2004 ; 171: 466-472$.

14. McDonald L, Kilgore G, Thompson A, Johnson S, Gerding D. Emergence of an epidemic strain of Clostridium difficile in the United States 2001-4: potential role for virulence factors and antimicrobial resistance traits. Presented at the 42 nd Annual Meeting of the Infectious Diseases Society of America; September 30-October 3, 2004; Boston, MA. Abstract LB-2. 
15. Warny M, Pepin J, Fang A, Killgore G, Thompson A, McDonald LC. Increased toxins A and B production in an emerging strain of Clostridium difficile. Presented at the 15th Annual Scientific Meeting of the Society for Healthcare Epidemiology of America; April 9-12, 2005; Los Angeles, CA. Abstract 313.

16. Eggertson L, Sibbald B. Hospitals battling outbreaks of $C$. difficile. CMAJ 2004;171:19-21.

17. Eggertson L. C. difficile: by the numbers. CMAJ 2004;171:1331-1332.

18. Ross E. British Authorities Probe Hospital Superbug. New York: ABC News; 2005. Available at abcnews.go.com/Health/wireStory?id $=828758$. Accessed July 5, 2005.

19. Sohn S, Climo M, Diekema D, et al. Varying rates of Clostridium difficile-associated diarrhea at Prevention Epicenter Hospitals. Infect Control Hosp Epidemiol 2005;26:676-679.

20. Palmore TN, Sohn S, Malak SF, Eagan J, Sepkowitz KA. Risk factors for acquisition of Clostridium difficile-associated diarrhea among outpatients at a cancer hospital. Infect Control Hosp Epidemiol 2005; 26:680-684.

21. Modena S, Bearelly D, Swartz K, Friedenberg FK. Clostridium diffcile among hospitalized patients receiving antibiotics: a case-control study. Infect Control Hosp Epidemiol 2005;26:685-690.

22. Rexach CE, Tang-Feldman YJ, Cohen SH. Spatial and temporal analysis of Clostridium difficile infection in patients at a pediatric hospital in California. Infect Control Hosp Epidemiol 2005;26:691-696.

23. Archibald LK, Banerjee SN, Jarvis WR. Secular trends in hospitalacquired Clostridium difficile disease in the United States, 1987-2001. J Infect Dis 2004;189:1585-1589.

24. McDonald LC, Banerjee S, Jernigan DB. Increasing incidence of Clos- tridium difficile-associated disease in U.S. acute care hospitals, 19932001. Presented at the 14th Annual Scientific Meeting of the Society for Healthcare Epidemiology of America; April 17-20, 2004; Philadelphia, PA. Abstract 67.

25. Kralovic SM, Danko LH, Simbartl LA, Roselle GA. Clostridium diffcile infection in VA medical centers nationwide. Presented at the 15th Annual Scientific Meeting of the Society for Healthcare Epidemiology of America; April 9-12, 2005; Los Angeles, CA. Abstract 284.

26. Delmee M, Van Broeck J, Simon A, Janssens M, Avesani V. Laboratory diagnosis of Clostridium difficile-associated diarrhoea: a plea for culture. J Med Microbiol 2005;54(part 2):187-191.

27. Poutanen SM, Simor AE. Clostridium difficile-associated diarrhea in adults. CMAJ 2004;171:51-58.

28. Gaynes R, Rimland D, Killum E, et al. Outbreak of Clostridium difficile infection in a long-term care facility: association with gatifloxacin use. Clin Infect Dis 2004;38:640-645.

29. Muto CA, Pokrywka MF, Shutt K, et al. A large outbreak of Clostridium difficile-associated disease with an unexpected proportion of deaths and colectomies at a teaching hospital following increased fluoroquinolone use. Infect Control Hosp Epidemiol 2005;26:273-280.

30. Garner JS. Guideline for isolation precautions in hospitals: the Hospital Infection Control Practices Advisory Committee. Infect Control Hosp Epidemiol 1996;17:53-80.

31. Boyce JM, Pittet D. Guideline for hand hygiene in healthcare settings: recommendations of the Healthcare Infection Control Practices Advisory Committee and the HICPAC/SHEA/APIC/IDSA Hand Hygiene Task Force. Infect Control Hosp Epidemiol 2002;23(suppl):S3S40.

\section{CORRECTION}

In the June issue of the Journal, Tables 5 and 6 of the article "Excess Mortality, Hospital Stay, and Cost Due to Candidemia: A Case-Control Study Using Data From Population-Based Candidemia Surveillance" by Morgan et al. were incomplete.

Regarding Table 5, the following should have appeared below the line "Candidemia with adequate treatment":

$$
\text { Age group } 0-4 \text { y } \quad+34,698 \quad+54,330 ;+20,421 \quad \leqslant .05 \quad+16,973 \quad+25,462 ;+10,136 \quad \leqslant .05 \text {. }
$$

Regarding Table 6, the following should have appeared below the line "Candidemia with adequate treatment":

$$
\text { Age group } 0-4 \mathrm{y} \quad+18,911 \quad+29,610 ;+11,129 \quad+12,967 \quad+19,453 ;+7,744
$$

